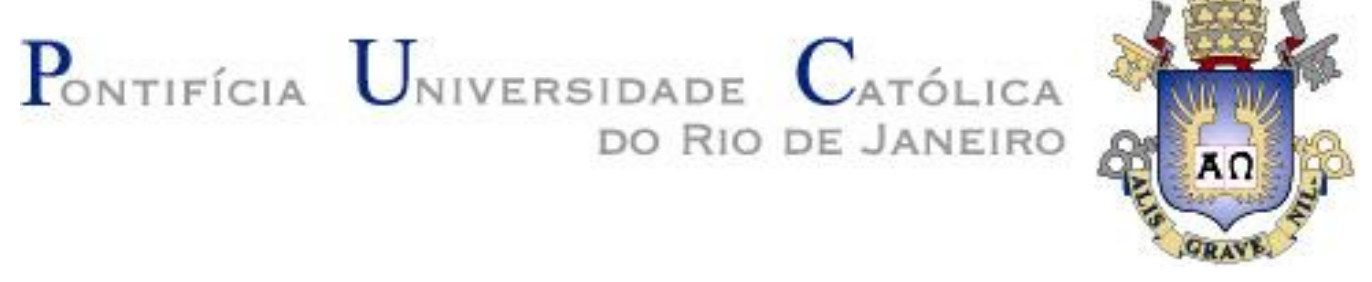

Alain Monteiro de Mello

\title{
Avaliação da Licitação de Lotes de Frequência para LTE Utilizando a Teoria de Opções Reais
}

\section{Dissertação de Mestrado (Opção profissional)}

Dissertação apresentada como requisito parcial para obtenção do título de Mestre pelo Programa de Pós-Graduação em Administração da PUC-Rio.

Orientador: Prof. Luiz Eduardo Teixeira Brandão 


\section{Pontifícia Universidade C $_{\text {atólica }}$

Alain Monteiro de Mello

\section{Avaliação da Licitação de Lotes de Frequência para LTE Utilizando a Teoria de Opções Reais}

Dissertação apresentada como requisito parcial para obtenção do título de Mestre pelo Programa de PósGraduação em Administração da PUC-Rio. Aprovada pela Comissão Examinadora abaixo assinada.

Prof. Luiz Eduardo Teixeira Brandão

Orientador

Departamento de Administração - PUC-Rio

Prof. Leonardo Lima Gomes

Departamento de Administração - PUC-Rio

Prof. Celso Lemme

UFRJ

Prof. Carlos Bastian

IBMEC RJ

Prof. Mônica Herz

Coordenador(a) Setorial do Centro de Ciências Sociais - PUC-Rio 
Todos os direitos reservados. É proibida a reprodução total ou parcial do trabalho sem autorização da universidade, do autor e do orientador.

\section{Alain Monteiro de Mello}

Graduou-se em Engenharia de Produção Elétrica na PUC-Rio em 2008.

Ficha Catalográfica

Mello, Alain Monteiro de

Avaliação da licitação de lotes de frequência para LTE utilizando a teoria de opções reais / Alain Monteiro de Mello ; orientador: Luiz Eduardo Teixeira Brandão. - 2013.

76 f. : il. (color.) ; $30 \mathrm{~cm}$

Dissertação (mestrado)-Pontifícia Universidade Católica do Rio de Janeiro, Departamento de Administração, 2013.

Inclui bibliografia

1. Administração - Teses. 2. Opções reais. 3. Finanças.

4. Análise de investimentos. 5. Avaliação de projetos. 6. Telecomunicações. I. Brandão, Luiz Eduardo Teixeira. II. Pontifícia Universidade Católica do Rio de Janeiro. Departamento de Administração. III. Título.

CDD: 658 


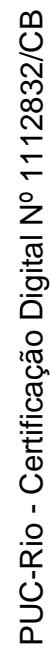

À minha família. 


\section{Agradecimentos}

Aos meus pais, Anderson e Lidia, pela educação, apoio, incentivo e carinho por toda a vida, sem os quais a elaboração deste trabalho não seria possível.

Ao meu orientador Professor Luiz Eduardo Teixeira Brandão, pela paciência e importantes contribuições para o trabalho.

À Juliana, pela atenção, companhia e carinho.

A todos os amigos, familiares, professores e colegas que de alguma forma me ajudaram. 


\section{Resumo}

Mello, Alain Monteiro de; Brandão, Luiz Eduardo Teixeira. Avaliação da Licitação de Lotes de Frequência para LTE Utilizando a Teoria de Opções Reais. Rio de Janeiro, 2013. 76p. Dissertação de Mestrado Departamento de Administração, Pontifícia Universidade Católica do Rio de Janeiro.

Em setores dinâmicos como o de telecomunicações, muitas vezes o uso das ferramentas tradicionais de avaliação de projetos mostram-se muito limitados, pois não capturam o valor das possíveis flexibilidades gerenciais. Este trabalho buscou apresentar a teoria das opções reais e aplica-la em um caso real. Para tanto foram avaliados os lotes de frequência LTE - Long Term Evolution, padrão tecnológico de banda larga móvel que oferece velocidades de taxa de transmissão de dados muito superiores às disponíveis atualmente - licitados em 2012 tanto pelo método tradicional de FCD quanto pela teoria das opções reais, do ponto de vista estratégico da operadora Oi. Por fim, foram comparadas as duas metodologias. Os resultados indicam que a avaliação por opções reais alterou a decisão de compra de alguns lotes, pois ao incorporar flexibilidade gerencial às avaliações, foram capturados valores significativamente maiores às mesmas. Concluímos que uma maior difusão desta metodologia no setor poderia melhorar a qualidade das decisões de investimento de capital.

\section{Palavras-chave}

Opções Reais; Finanças; Análise de Investimentos; Avaliação de Projetos; Telecomunicações. 


\section{Abstract}

Mello, Alain Monteiro de; Brandão, Luiz Eduardo Teixeira (Advisor). Frequency Lots Bidding Evaluation for LTE Using Real Options Theory. Rio de Janeiro, 2013. 76p. MSc. Dissertation - Departamento de Administração, Pontifícia Universidade Católica do Rio de Janeiro.

In dynamic sectors such as telecommunications, often the use of traditional project evaluation tools is very limited, as they do not capture the value of managerial flexibility. This study presents the real options theory and applies it to a real case. To do this, we evaluated the LTE - Long Term Evolution - frequency lots, a technology standard for mobile broadband that offers significantly higher speed rates of data transmission than those currently available, auctioned in 2012 by both the traditional method of FCD and the real options theory, from the strategic point of view of operator Oi. Finally, the two methods are compared. The results indicate that the real options valuation altered the purchasing decision of some lots, because after incorporating the managerial flexibility on the valuations the value captured was significantly higher. We conclude that greater diffusion of the method in this sector could improve the quality of capital investment decisions.

\section{Keywords}

Real Options; Finance; Investment Analysis; Project Evaluation; Telecommunications. 


\section{Sumário}

1 Introdução 12

1.1. Contextualização 12

1.2. Objetivo do Estudo 13

1.3. Relevância do Estudo 13

1.4. Estrutura da Dissertação 14

2 Referencial Teórico 15

2.1. Avaliações Tradicionais 15

2.2. Opções Financeiras 18

2.2.1. Modelo de Black \& Scholes 20

2.2.2. Modelo Binomial 21

2.3. Teoria das Opções Reais 23

2.4. Revisão da Literatura 26

3 A Oi, a Tecnologia LTE e o Leilão de Frequências 29

3.1. A Oi 29

3.2. O que é LTE 30

3.3. Espectros de Frequência 30

3.4. Ambiente Regulatório 32

3.4.1. Regras do Leilão 32

3.4.2. Cronograma de Obrigações 34

3.5. Resultados do Leilão 36

4 Avaliação das Faixas de Frequência 39

4.1. O Projeto 39

4.1.1. Modelagem 39

4.1.2. Projeções 40

4.1.3. Incertezas e Riscos $\quad 40$

4.2. Avaliação Tradicional 41

4.3. Avaliação por Opções Reais 45 
5 Resultados das Modelagens

6 Conclusões e Recomendações $\quad 57$

6.1. Conclusões $\quad 57$

6.2. Sugestões para Trabalho Futuros 58

7 Referências Bibliográficas $\quad 59$

8 Anexos $\quad 62$ 


\section{Lista de figuras}

Figura 1 - Modelo Binomial de Dois Passos 22

Figura 2 - Dinâmica do Leilão LTE 32

Figura 3 - Loteamento das Frequências LTE no Brasil 33

Figura 4 - Detalhamento dos Lotes LTE Nacionais 36

Figura 5 - Evolução do ARPU LTE 46

Figura 6 - Evolução de Cliente LTE Oi 47

Figura 7 - Evolução do Valor dos Equipamentos em Relação ao $1^{\circ}$ Ano

Figura 8 - Distribuição de Retornos do Lote LTE Nacional de $10+10 \mathrm{MHz} \quad 49$

Figura 9 - Distribuição de Retornos do Núcleo LTE do CN 11

Figura 10 - Distribuição de Retornos do Núcleo LTE do CN 51

Figura 11 - Distribuição de Retornos do Núcleo LTE do CN 81

Figura 12 - Árvore Binomial do Lote LTE Nacional $10+10 \mathrm{MHz}$

Figura 13 - Árvore Binomial do Núcleo do CN 11

Figura 14 - Árvore Binomial do Núcleo do CN 51

Figura 15 - Árvore Binomial do Núcleo do CN 81

Figura 16 - VPL dos Lotes Regionais Complementares e

Valor das Opções

Figura 17 - VPL dos Lotes Regionais (complemento e núcleo) com e sem Opção

Figura 18 - VPL do Lote V com e sem Opção 56 


\section{Lista de tabelas}

Tabela 1 - Modelo de Fluxo de Caixa da Empresa 15

Tabela 2 - Efeitos Sobre o Valor das Opções 19

Tabela 3 - Opções Financeiras vs. Opções Reais 24

Tabela 4 - Faixas de Frequências Utilizadas para LTE por Operadora 31

Tabela 5 - Cronograma de Obrigações $2,5 \mathrm{GHz}$

Tabela 6 - Cronograma de Obrigações 3G 35

Tabela 7 - Cronograma de Obrigações $450 \mathrm{MHz}$

Tabela 8 - Resultados do Leilão de Lotes LTE Nacionais 37

Tabela 9 - Resultados do Leilão de Lotes LTE Regionais

(Complementos) 37

Tabela 10 - Avaliação dos Lotes LTE Nacionais e Lance Máximo 41

Tabela 11 - Avaliação dos Lotes LTE Nacionais e Lance

Máximo Adaptado 42

Tabela 12 - Avaliação dos Lotes LTE Regionais (Complemento) 43

Tabela 13 - Avaliação dos Lotes LTE Regionais (Núcleo) 44

Tabela 14 - Avaliação Conjunta dos Lotes LTE Regionais 44

Tabela 15 - VP0 Com e Sem Opções e Valor das Opções 54 